\title{
An Algorithm Approach for the Analysis of Urban Land-Use/Cover: Logic Filters
}

\author{
Sinasi Kaya ${ }^{1,}{ }^{*}$, Fikret Pekin ${ }^{2}$, Dursun Zafer Seker ${ }^{1}$, Aysegul Tanik ${ }^{3}$ \\ ${ }^{1}$ Istanbul Technical University, Civil Engineering Faculty, Department of Geomatics, 34469, MASLAK, ISTANBUL-TR \\ ${ }^{2}$ Istanbul Technical University, Informatics Institute, 34469, MASLAK, ISTANBUL-TR \\ ${ }^{3}$ Istanbul Technical University, Civil Engineering Faculty, Department of Environmental Engineering, 34469, MASLAK, \\ ISTANBUL-TR
}

\begin{abstract}
Accurate classification of land-use/cover based on remotely sensed data is important for interpreters who analyze time or event-based change on certain areas. Any method that has user flexibility on area selection provides great simplicity during analysis, since the analyzer may need to work on a specific area of interest instead of dealing with the entire remotely sensed data. The objectives of the paper are to develop an automation algorithm using Matlab \& Simulink on user selected areas, to filter V-I-S (Vegetation, Impervious, Soil) components using the algorithm, to analyze the components according to upper and lower threshold values based on each band histogram, and finally to obtain land-use/cover map combining the V-I-S components. LANDSAT 5TM satellite data covering Istanbul and Izmit regions are utilized, and 4, 3, 2 (RGB) band combination is selected to fulfill the aims of the study. These referred bands are normalized, and V-I-S components of each band are determined. This methodology that uses Matlab \& Simulink program is equally successful like the unsupervised and supervised methods. Practices with these methods that lead to qualitative and quantitative assessments of selected urban areas will further provide important spatial information and data especially to the urban planners and decision-makers.
\end{abstract}

Keywords: Istanbul, District, Landsat, Matlab \& Simulink, Remote Sensing

\section{Introduction}

Remotely sensed data is among the significant data types used in classifying land cover and land-use distribution. Most of the applications and researches are in need of information and data on the types and distribution of land cover. Many researchers conducted studies on the use of land cover in especially urban areas and on obtaining information regarding land cover that would further lead to both qualitative and quantitative analysis of the findings (Welch and Ehlers 1987; Pathan et al., 1993; Dimyati et al., 1996). Remotely sensed data has gained broad utility in particularly urbanized areas. A variety of studies on urban morphology focus on land cover data analysis where the data used is obtained through satellite images (Jensen and Toll 1982; Forster and Jones 1988; Kaya and Curran 2006; Kaya et al., 2004; Kaya, 2007). It is very important for the analyst to obtain and organize these data in the numerical form. A piece of land cover can be observed in a visualized form; however, when the data is converted to digital form, it becomes easier to follow any land-use changes and such changes can therefore be better understood. VIS (Vegetation-Impervious-Soil) Model is one of the methods used for this purpose.

VIS model has been developed to detect morphological structures of urbanized areas. The model specify the urban land mainly as a linear combination of three components. Ridd (1995) has put forth the applicability of the VIS model in the analysis of urban morphology, biophysical and human-induced systems. In this model analysis, remotely sensed data is utilized, and it is of practical use in exhibiting the temporal changes of land-use/cover at the analyzed areas. As such, temporal analyses exert the land distribution changes not only for 
the human-induced activities, but also the impacts of natural disasters like earthquakes and flooding can also be easily determined. Additionally, an analyst may conduct the analyses through a computer by inspecting data obtained by means of satellite images and easily may put forth the results even without carrying out thorough and broad field visits. The VIS model applications benefit from satellite images in that sense. This model has been initially practiced in the Salt Lake City by Ridd (1995), followed Ward et al. (2000), Madhavan et al. (2001), and Setiawan and Mathieu (2006) who have tested it in different cities of the world. The model may be simultaneously applied to produce concrete data that indicate urban changes by using different classification methodologies. Even though the methodologies differ for various different applications, most of them would require an important time span. The most common methods used to classify landuse/cover are supervised and unsupervised classification methods. Supervised classification is a classification method that directs the software by inserting some particular properties that will be needed by the user in image processing. This routing is usually realized by using test polygons. In the unsupervised classification, the image is processed by the software, and the user determines on how he/she will categorize the emerging classes. However, all these methods take into consideration the risk of different land-use types existing within the same pixel. Thus, findings derived from data with low spatial resolution may not include high precision.

Fuzzy classification and Linear Spectral Mixture Analysis (LSMA) are among the methods used to solve the pixel problem. LSMA model is used to separate end members' present in the pixel in a deterministic manner (Boardman et al., 1995). End members are land materials that exhibit homogenous spectral character along the image. Based on this character, LSMA is used in estimating land cover (Small 2001; Weng et al., 2004; Lee and Lathrop, 2005), impervious land and urban morphology analysis (Phinn et al., 2002; Wu et al., 2005; Lu and Weng, 2006), vegetation cover and land classification ( $\mathrm{Lu}$ and Weng,
2006), in tracking land-use changes (Powell et al., 2007), and in other similar applications (Melesse et al., 2007).

Another important factor to be considered in the classification of land-use/cover is the selection of the area concerned by the user. Many of the applications grant a limited study area when analysis is required for some particular areas of the data set. However, the user may require selection of some areas from the same data set and conduct the analyses at areas apart from the selected areas. In this study, automation of VIS model is realized on satellite images of some areas selected by the user through the Matlab \& Simulink program, and maps of each individual component from the related images are generated. In order to fulfill this aim, images are divided into bands, and each of them are queried regarding their individual component information. Moreover, images of the bands are classified as Vegetation Cover- V-, Impervious Land- I-, and Soil-S.The findings indicate that the developed program is convenient for images with medium spatial resolution and that similar approximate results like the unsupervised classification method may be achieved more rapidly.

\section{Methodology Used}

\section{VIS model}

Urban environments are so heterogeneous; thus, it is necessary to simplify them as combinations of basic land cover components to enable quantitative studies. VIS model proposed by Ridd (1995) is a conceptual model to simplify urban environments as combination of three basic land cover components: Vegetation- V-, Impervious surface-I-, and Soil-S-. Most urban surfaces can be interpreted as combinations of these three basic components. VIS model classifies the three components by utilizing satellite images, and exhibits the percent weights of each component in the study area. As such, it is possible to exert any environmental changes that have occurred in a region by the application of this model. Details on the model may be better explained by Figure 1. Each of the axis of the triangle represent the three components. The values on the axes indicate the percent distribution of the component in the area of interest. When all the 
corresponding values are determined for the three components, the intersection point that lies within the triangle represent the current situation of the region considered (Hung, 2002). evaluators. Soil-vegetation axis rather indicates the urban land or land at transient condition. In rural land or land that has not yet been urbanized do not bear impervious land. Barren

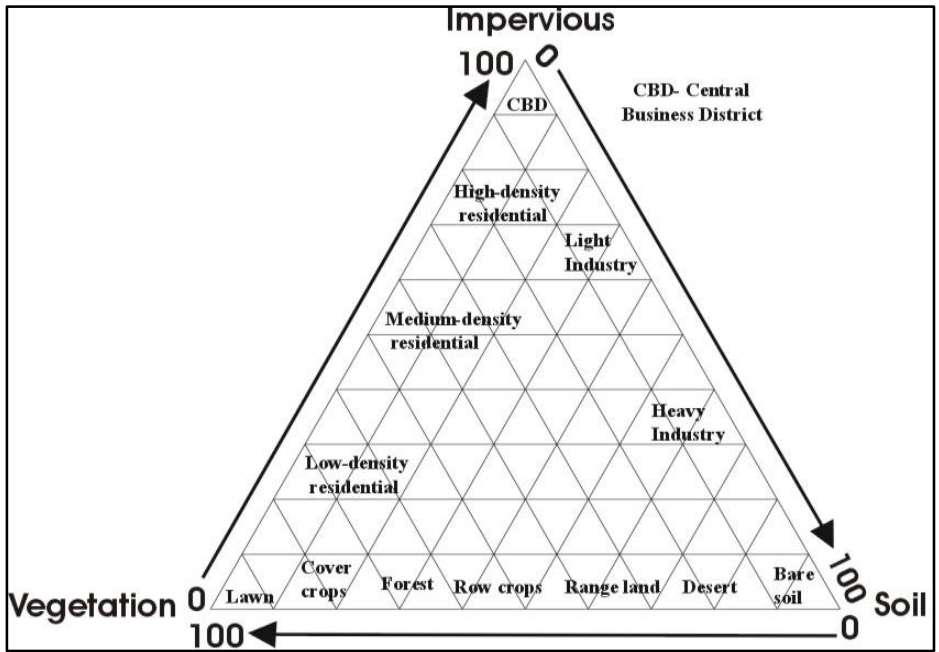

Fig 1. The V-I-S model (Ridd, 1995)

Various charts and plots are generated to demonstrate the capacity of V-I-S composition on urban land cover analysis. VIS model is highly used to differentiate urban land from rural land, and to conduct urban morphology of developed areas and other development studies. As shown in Figure 1, the main components of VIS are located at the corners of the triangle and a trio grid is used. It is actually a generalized schematic diagram of the urban land and its vicinity. The general land use terms are used in the diagram for proper understanding.

The priority issues of applying the model are to demonstrate the ecological, biophysical and scientific purposes of urban land use, and to identify and qualify the land cover models. Any sort of correlation is due to land use rather than VIS model. In the developing world, the typical settlements are arranged within the vegetationimpervious axis. Conventional commerce and industrial areas are usually established in the impervious-soil land while vegetation land is spared for agriculture. The land cover information exists in remotely sensed data and thus, this information is further analyzed and classified by the experts. Land-use is of environmental character; for example VIS presents various areas of urban land to the soil at the right hand corner indicates clean land that has started developing or new development areas in urban land. Desert and pasture land occupies part of vegetation cover and moves towards left extending from seeding to harvesting. Forests base on dense cover and the barren land amount varies with time and place. Continuous vegetation covers like clover and pasture, or green areas like golf areas, parks, school grassland take place at the left hand side. In an urban environment, most of the environmental elements exist together with green plantation; wildlife and aesthetic use are covered in VIS model that takes into account all the green vegetation cover. VIS describes the biophysical composition of an urban area as a function based on the three components and it provides a means of assessing the trend and relative magnitude of land cover change in an urban area. (Madhavan et al., 2001; Phinn et al., 2002).

One of the methods used to determine the percent areas of each of the three land surface components by means of VIS model is to take cross-sections of the satellite images to measure the areas devoted to $\mathrm{V}, \mathrm{I}, \mathrm{S}$. The key point at this stage is to increase the number of crosssections in order to come out with approximate percent values. Similarly, unsupervised and 
supervised classification methods may also be used to determine the percent distribution of the considered components with the available information. In this study, the aim is to provide analysis flexibility to the user by enabling the selection of any desired region on the satellite image, and to conduct micro-scale analysis on these selected regions. In order to fulfill this aim, Matlab \& Simulink 7.0 software is used in the developed program, and spectral filters are used to calculate the component-wise percentages. Each of the bands that pass through these filters indicate both areal values and supply percent distributions of each of the components (Kaya and Pekin, 2011; Kaya et al., 2012).

\section{New Algorithm Approach for the Analysis of Urban Land-Use/Cover}

This application that is developed by using the Matlab \& Simulink program enables the analyst to deal with highly small scale areas that will be selected by the user on the satellite images. Thus, the multi-spectral image on which the model will be applied contains 7 bands, and is formed of 3 main bands. Within the scope of the study, LANDSAT 5 TM satellite image with 7 bands is utilized belonging to 28 June 2007 covering the extremely urbanized Istanbul and Izmit regions in Turkey. The selected area on this image is the Izmit Bay area on which analyses are conducted that is formed of Green, Red and Near Infrared bands (Figure 2). The results of the analyses obtained by using the Matlab \& Simulink program are further classified by applying unsupervised and supervised classification methods by the help of Erdas Image Program. The outcomes achieved are exhibited in a comparative manner.

Further analyses are carried out on the selected area. The next step is to distinguish the image to green, red and near infrared bands, and to normalize the values appearing on these bands. Normalization process is followed by dividing the data on a single band to the sum of the data of all the considered bands. As such, four components will be put forth, one being the original image.

Minimum and maximum threshold values for each component is then determined on the histogram of each band. If the determined components exist on the image, the value of " 1 ", and if it does not appear in the image, the value of " 0 " is recorded on the emerging image (Figure 3). Filtered image may be obtained when the filters are multiplied by images that are used as input data. At this point, it is important to select the bands whose analyses are conducted. It is because each spectral band bears characteristic properties and information. As the information and data on vegetation cover- V-, impervious land- I-, and soil- S- do not exist in a single band in the same weight, conducting the analyses at different bands becomes important. In this study, analyses carried out by using the Matlab \& Simulink software consists of detecting the value each of the three components $(\mathrm{V}, \mathrm{I}, \mathrm{S}$,) on each of the bands by means of threshold values appearing on the histograms of the normalized bands that are supervised by the user.

\section{Results and Discussion}

Each of the three components are filtered by minimum and maximum threshold values at separate bands on the selected area. These filters bear logic properties regarding their pixel values. This is to say that pixel values of the filters is taken as " 1 " for the pixels of the related component, and is considered as " 0 " for other pixels that do not belong to a component. For correlation purpose, in the analyses conducted by mapping the filters obtained for each component from the three bands, the pixels that are mapped at least at two of the bands are accepted as existing pixels of the component. This overlapping consist of pixel values like 0", "1", "2" and "3" for the new filters that arise after processing. This analysis means that pixel values of " 2 " and " 3 " convey the related component. Pixels shown in light blue color in the figure are pixels with value " 1 " that contains the related component at a single band obtained separately by overlaying the component filters for each of the three bands. However, the blue colored pixels cover the related component in the two bands. Finally, red colored pixels, on the other hand, indicate that information is available for the related component in each of the three bands. At the end of such correlation, pixels with values " 2 " and " 3 " are filtered and the rest of 
the pixels are ignored (Pekin, 2010; Pekin and Kaya, 2010). The resulting situation of the three components are shown respectively in Figure 4. Vegetation cover is illustrated in Figure $4 a$ as green, impervious land as red in Figure $4 b$, and soil as yellow in Figure 4c. The combination of $\mathrm{V}$-I-S land-use component is shown in Figure $4 d$.

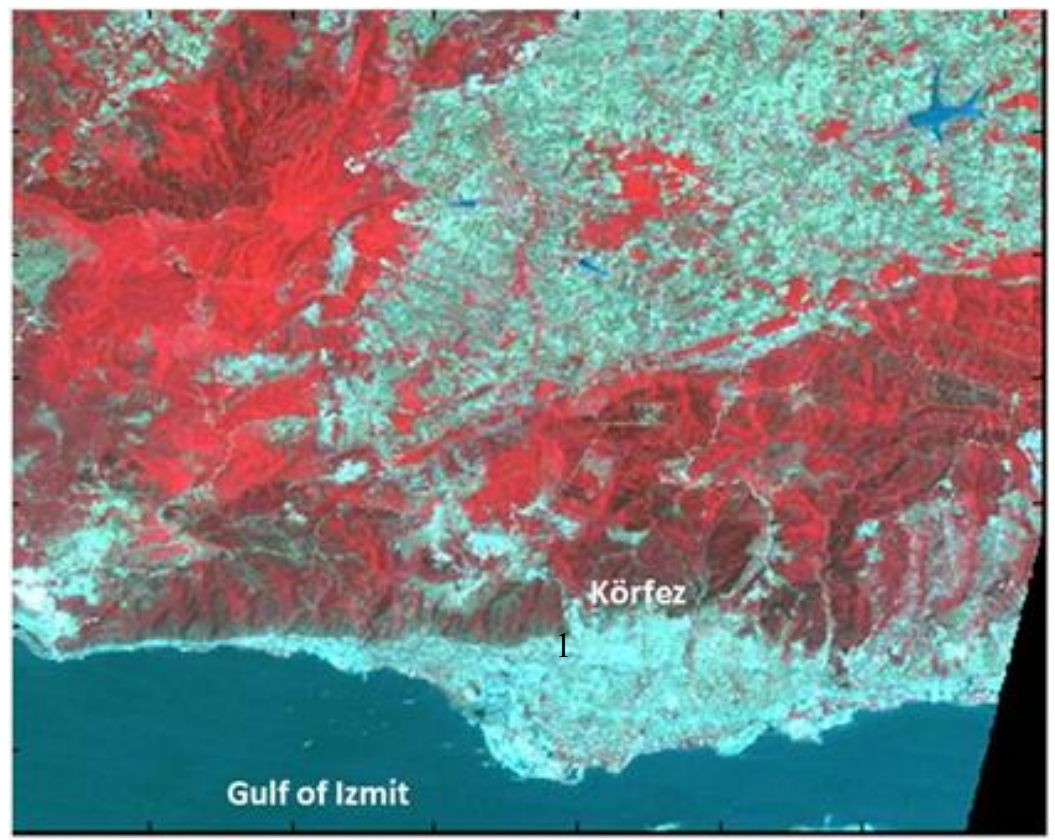

Fig 2. Selected Area from LANDSAT 5 TM Image (Bands 4, 3, 2)

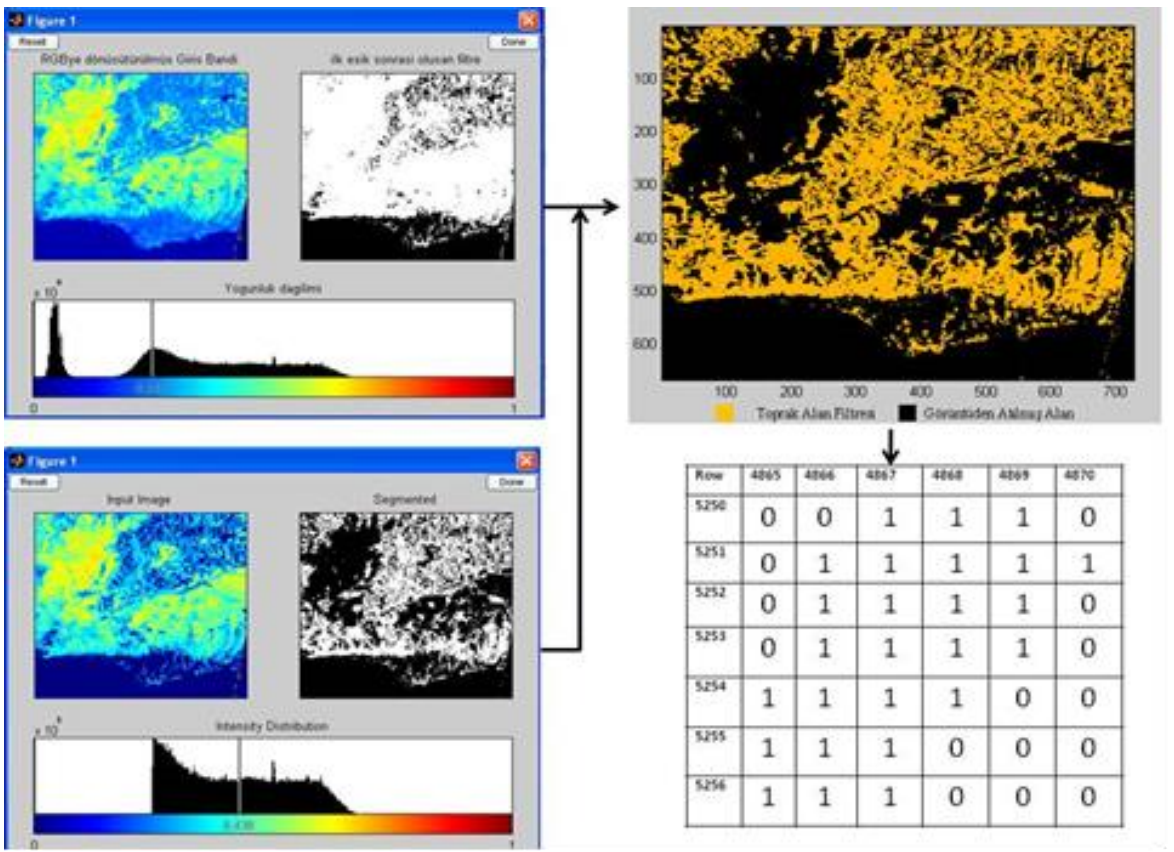

Fig 3. Coding and querying a component at the selected band according to minimum and maximum values (example of soil component- S-) 
The resulting percent distribution of the three components are found as $32.99 \%$ for vegetation cover, $12.12 \%$ for impervious land, $39.16 \%$ for soil layer, and $14.87 \%$ for water surface. Water surface is not taken into account during the evaluations. The sum of these distribution percentages lead to a value of $99.14 \%$. The total surface area selected for this study is calculated from the image as $435.763 \mathrm{~km}^{2}$. Thus, similarly the area covered by vegetation is found as
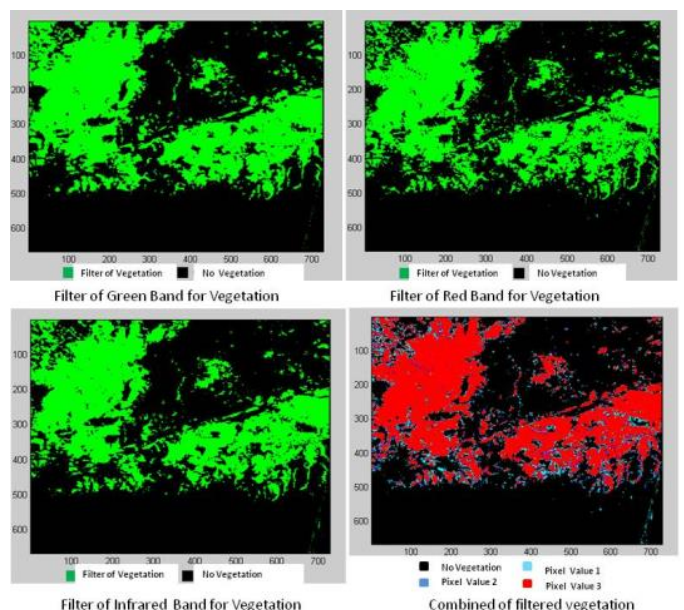

Filter of Ped Band for Vegetation

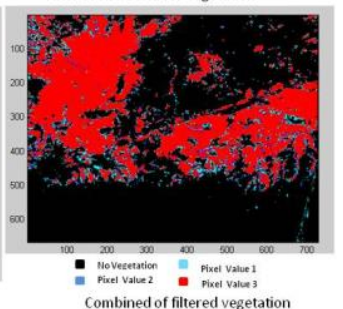

(a)
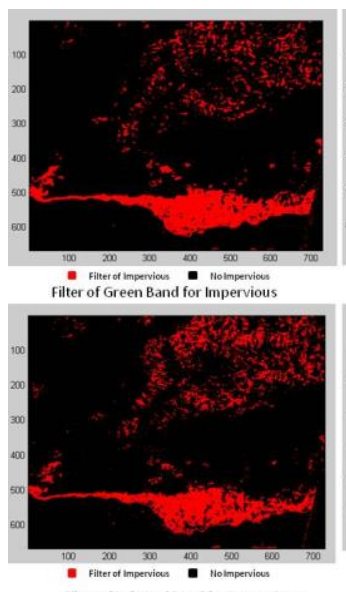

Filter of Infrared Band for Impervious

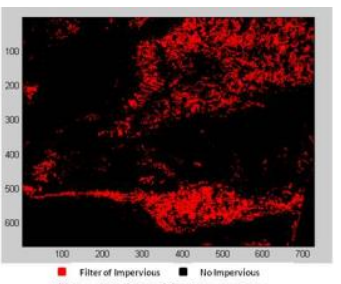

Filter of Red Band for Impervious

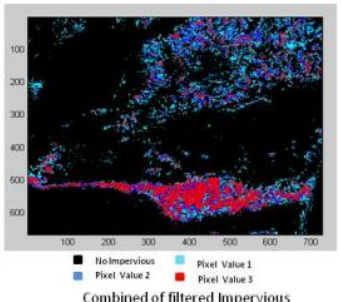

(c)
$143.76 \mathrm{~km}^{2}$, impervious land occupies an area of $52.844 \mathrm{~km}^{2}$, soil land of $170.65 \mathrm{~km}^{2}$ and water surface of $64.779 \mathrm{~km}^{2}$. Supervised and unsupervised classification method is also applied to the same satellite image for comparing the results. The results are given in Table 1. It can easily be seen from this table that the similar results are obtained through application of different methodologies to the same image.

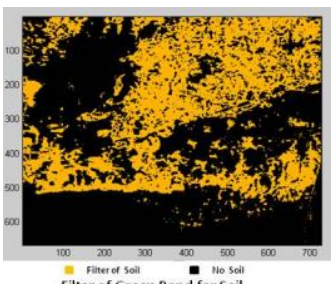

Fitter of Green Band for Soil

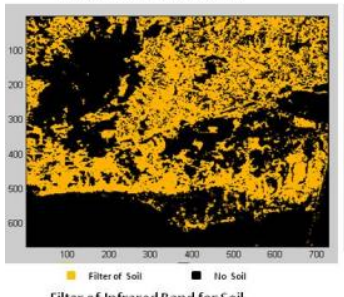

Filter of Infrared Band for Soil

(b)
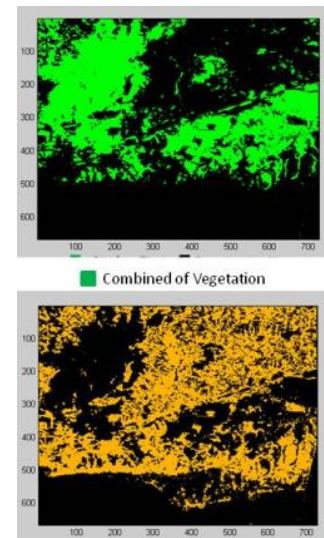

[1] Combined of Soil
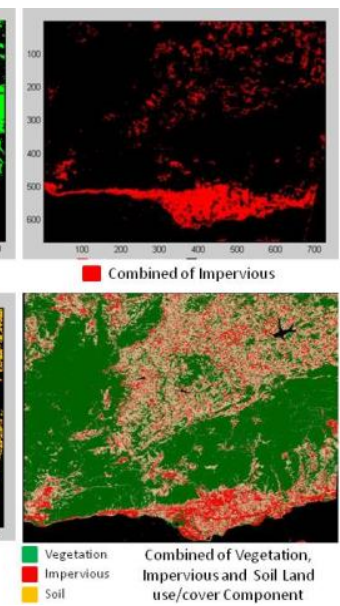

(d)
Combined of Impervious
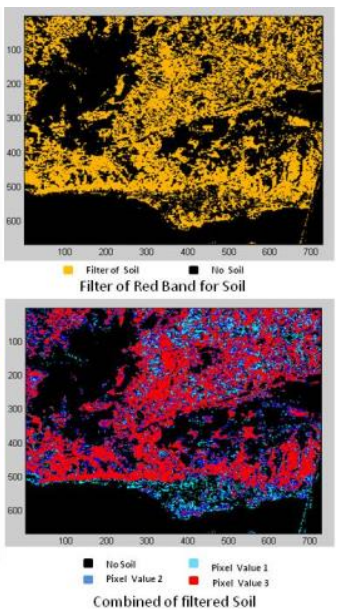

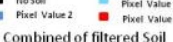
use/cover Component

(d)

Fig 4. a) Filtered vegetation cover, b) Filtered impervious land, c) Filtered soil layer, d) Combination of V-I-S

Land- use/cover component. 


\begin{tabular}{|c|c|c|c|c|c|}
\hline $\begin{array}{l}\text { VIS } \\
\text { Components }\end{array}$ & $\begin{array}{l}\text { Unsupervised } \\
\text { classification } \\
\%\end{array}$ & $\begin{array}{l}\text { Supervised } \\
\text { classification } \\
\%\end{array}$ & $\begin{array}{ll}\text { Matlab } \quad \& \\
\text { Simulink } & \\
\text { Results } & \\
\% & \end{array}$ & $\begin{array}{l}\text { Difference } \\
\text { between the } \\
\text { model and } \\
\text { unsupervised } \\
\text { classification } \\
\%\end{array}$ & $\begin{array}{l}\text { Difference } \\
\text { between the } \\
\text { model and } \\
\text { supervised } \\
\text { classification } \\
\%\end{array}$ \\
\hline $\begin{array}{l}\text { Vegetation } \\
\text { cover } \\
\text { Impervious }\end{array}$ & 35.3 & 34.3 & 33.0 & 2.3 & 1.3 \\
\hline land & 14.9 & 11.9 & 12.1 & 2.8 & 0.2 \\
\hline Soil & 34.6 & 38.4 & 39.2 & 4.6 & 0.8 \\
\hline $\begin{array}{l}\text { Water (apart } \\
\text { from VIS } \\
\text { component) }\end{array}$ & 15.2 & 15.4 & 14.9 & 0.5 & 0.3 \\
\hline
\end{tabular}

Table 1. Results of Supervised and Unsupervised Classification and Comparison of the Classification Results with Matlab \& Simulink Findings

\section{Conclusions}

Attaining information on land-use/cover is of high importance for urban morphology and region planning. It is possible to provide these information in the most rapid and economic way by utilizing multi-spectral satellite images. Many methods are applicable for this purpose. In this study, logical filters applied by Matlab \& Simulink software are used to analyze various bands. The results show a variable trend according to the spectral characteristics of the bands. These differences are overcome after relating the results for each band, and thus the accuracy of the results increase. Moreover, the precision attained during application of the methodology is directly proportional with the threshold values determined by the user on the image. When the results of this study are compared with the results gained through the application of supervised and unsupervised classification applied by Erdas image lead to a similarity above $90 \%$. This situation indicates that the model used in this study is reliable. This methodology that is applied by using Matlab \& Simulink software enables the possibility of selecting various regions on the image and thus, it provides a flexibility to analyze different points on the same image. It is particularly determined that in areas with mixed pixels, these pixels could not be separated. In order to overcome this difficulty, the minimum and maximum threshold values must be found through iteration. Also, it will be possible to better define the obtained data by filtering the component at various threshold values selected by the user rather than filtering the selected two thresholds. As such, the data will be more accurately displayed. Some problems have arisen during processing of the image data with high resolution due to memory constraints. However, the results on determination of the land components of the study area are achieved in a less time span compared to supervised and unsupervised classification methodology.

As interest to urban environment has increased, some standards of biophysical parameters are required apart from land-use distribution regarding the ecological assets. Digital multispectral satellite technology nowadays provides valuable opportunities for qualifying, quantifying and comparing different urban components in especially the urbanized areas in the world. Vegetation-Impervious land-Soil (VIS) model proposes the fundamentals of standardization, comparison and variation in the urbanized ecosystems. As such, the model presents data to be further utilized and benefitted by scientists, environmental managers and urban planners. 


\section{References}

Boardman, JW., Kruse, FA. (1995). Mapping target signature via partial unmixing of AVIRIS data. Summaries of the 5th JPL Airborne Earth Science Workshop; JPL Publication 95-1, NASA Jet Propulsion Laboratory, Pasadena, Calif., 1995; pp. 2326.

Dimyati, M., Mizuno, K., Shintaro, K., Kitamur, T. (1996). An analysis of land use/cover change using the combination of MSS Landsat and land use map - a case study in Yogyakarta, Indonesia, International Journal of Remote Sensing, 17: 931-944.

Forster, BC., Jones, C. (1988). Urban density monitoring using high resolution space borne system, Com. VII (Kyoto: ISPRS), pp: 189-195.

Hung, MC. (2002). Urban land cover analysis from satellite images, Pecora 15/Land Satellite Information IV/ISPRS Commission I/FIEOS 2002, Conference Proceedings, $\mathrm{p} 1$.

Jensen, JR., Toll, DL. (1982). Detecting residential land-use development at the urban fringe, Photogrammetric Engineering and Remote Sensing, 48: 629-643.

Kaya S., Pekin F., Seker DZ. (2013). Automation of V-I-S model Using Matlab \& Simulink on user selected areas, ACRS 2013, Proceedings in CD, 20-24 October, Bali, Indonesia.

Kaya, S. (2007). Multitemporal Analysis of Rapid Urban Growth in Istanbul Using Remotely Sensing Data, Environmental Engineering Science, 24(2): 228-233.

Kaya, S., Curran, PJ. (2006). Monitoring urban growth on the European side of the Istanbul metropolitan area: a case study, International Journal of Applied Earth Observation and Geoinformation, 8(1): 1825.

Kaya, S., Llewellyn, G., Curran, PJ. (2004). Displaying earthquake damage on an urban area using a V-I-S model and remotely sensed data, XXth Congress of the International Society for Photogrammetry and Remote Sensing (ISPRS), 2004, 12-25 July, Istanbul, Turkey.
Kaya, S., Pekin, F. (2011). Use of logic filters in remote sensing: an application on V-I-S model, 13th Turkish Scientific and Technical Mapping Congress, Proceedings in CD, 18-22 April, Ankara. (in Turkish).

Kaya, S., Seker, DZ., Tanik, A. (2012). Analysis of urbanized areas using V-I-S components model, Fresenius Environmental Bulletin, 21(11): 3243-3248.

Lee, S.; Lathrop, RG. Jr. (2005). Sub-pixel estimation of urban land cover components with linear mixture model analysis and Landsat Thematic Mapper imagery, International Journal of Remote Sensing, 26(22): 4885-4905.

Lu, D., Weng, Q. (2006). Use of impervious surface in urban land use classification, Remote Sensing of Environment, 102(12):146-160.

Madhavan, BB., Kubo, S., Kurisaki, NT., Sivakumar, VLN. (2001). Appraising the anatomy and spatial growth of the Bangkok Metropolitan area using a vegetation-impervious-soil model through remote sensing, International Journal of Remote Sensing, 22: 789-806.

Melesse, AM., Weng Q., Thenkabail PS., Senay GB. (2007). Remote sensing sensors and applications in environmental resources mapping and modeling, Sensors 2007, 7: 3209-3241.

Pathan, S.K., Sastry, SVC, Dhinwa, PS, Rao, M., Mujumdar, KL., Kumar, DS., Patkar, VN., Phatak, VN. (1993). Urban growth trend analysis using GIS techniques - a case study of the Bombay Metropolitan Region, International Journal of Remote Sensing, 14: 3169-3179.

Pekin, F., Kaya, S. (2010). Automation of V-I$S$ model using Matlab \& Simulink, Third Remote Sensing and Geographical Information Systems Symposium, UZALCBS, Proceedings in CD, 11-13 October, Gebze-Kocaeli, pp. 428-435. (in Turkish).

Pekin, FH. (2010). Automation of V-I-S model using Matlab \& Simulink, M.Sc. Thesis, ITU Informatics Institute, MaslakIstanbul.(in Turkish). 
Phinn, S., Stanford, M., Scarth, P., Murray, AT., Shyy, PT. (2002). Monitoring the composition of urban environments based on the vegetation-impervious surface-soil (VIS) model by sub pixel analysis techniques, International Journal of Remote Sensing, 20: 4131-4153.

Powell, RL., Roberts, DA., Dennison, PE., Hess, LL. (2007). Sub-pixel mapping of urban land cover using multiple end-member spectral mixture analysis: Manaus, Brazil. Remote Sensing of Environment 2007, 106(2): 253-267.

Ridd, MK. (1995). Exploring a V-I-S model for urban ecosystem analysis through remote sensing: comparative anatomy for cities, International Journal of Remote Sensing, 16: 2165-2185.

Setiawan, E., Mathieu, R. (2006). Assessing the applicability of the V-I-S model to map urban land use in the developing world: Case study of Yogyakarta, Indonesia, Computers, Environment and Urban Systems, 30(4): 503-522.
Small, C. (2001): Estimation of urban vegetation abundance by spectral mixture analysis, International Journal of Remote Sensing 2001, 22: 1305-1334.

Ward, D., Phinn, SR., Murray, AT. (2000). Monitoring growth in rapidly urbanizing areas using remotely sensed data, The Professional Geographer, 53: 371-386.

Welch, R., and Ehlers, M. (1987). Merging multi-resolution SPOT HRV and Landsat TM data, Photogrammetric Engineering and Remote Sensing, 52: 301-303.

Weng, Q., Lu, D., Schubring. J., (2004). Estimation of land surface temperaturevegetation abundance relationship for urban heat island studies, Remote Sensing of Environment 2004, 89: 467-483.

Wu, C., Murray, A.T. (2003). Estimating impervious surface distribution by spectral mixture analysis, Remote Sensing of Environment 2003, 84: 93-505. 